\title{
Isolation and pathotyping of Newcastle disease virus isolated from birds in Kerala*
}

\author{
(iD) \\ U. Rashi ${ }^{1 * \star}$, M. Mini², P. M. Priya ${ }^{3}$, Surya Sankar ${ }^{4}$ and K. Vijayakumar ${ }^{5}$ \\ Department of Veterinary Microbiology, \\ College of Veterinary \& Animal Sciences, Mannuthy, Thrissur 680651 \\ Kerala Veterinary and Animal Sciences University, Kerala, India.
}

Citation: Rashi, U., Mini, M., Priya, P. M., Sankar, S. and Vijayakumar, K. 2021. Isolation and pathotyping of Newcastle disease virus isolated from birds in Kerala. J. Vet. Anim. Sci. 52(3): 245249. DOI: https://doi.org/10.51966/jvas.2021.52.3.245-249

Received: 18.01.2021

Accepted: 26.03.2021

Published: 30.09 .2021

\section{Abstract}

Newcastle disease (ND) is a pandemic viral disease of poultry. It is highly contagious and causes high morbidity and mortality in affected flocks. The disease is caused by Avian orthoavulavirus 1, commonly known as Newcastle disease virus (NDV) belongs to the family Paramyxoviridae. The virus affects almost 241 species of birds. Based on the pathogenicity, the virus is classified into five pathotypes viz., viscerotropic velogenic, neurotropic velogenic, mesogenic, lentogenic and asymptomatic enteric NDV. The severity of the disease varies with the viral pathotype. Isolation and identification along with pathotyping of the virus provides a basis for understanding the type of virus circulating in the region. In the present study, tissue samples from dead/ ailing birds showing lesions/clinical signs suggestive of ND were collected. They were subjected to virus isolation in embryonated chicken eggs and identified by haemagglutination test and confirmed by haemagglutination inhibition test. Eight NDV isolates were obtained out of 55 tissue samples and were classified into pathotypes by intracerebral pathogenicity index (ICPI) and mean death time (MDT). The ICPI values varied from 0.75 to 1.53 and MDT from $54 \mathrm{~h}$. to $79.2 \mathrm{~h}$. Out of eight isolates, three belonged to velogenic group and five were of mesogenic pathotype. The study revealed the circulation of virulent NDV in Kerala. The pathogenicity tests provide a basis for understanding the epidemiology of ND.

Keywords: Haemagglutination test, intracerebral pathogenicity index, mean death time

Newcastle disease (ND), caused by Newcastle disease virus (NDV), is an affliction which causes severe losses in both commercial and backyard poultry production (Alexander, 1997). It is one of the 'Word Organization for Animal Health' listed notifiable disease, which affects international trade and is responsible for major constraint in world economy. According to International Committee on Taxonomy of Viruses report of 2018, NDV is officially known as Avian orthoavulavirus 1 (AOAV-1) and belongs to the genus Orthoavulavirus of the family Paramyxoviridae. It is known to infect almost 27 out of 50 orders of avian species, but the severity of the disease varies with the strain of the

${ }^{*}$ Part of M.V.Sc thesis submitted by the first author to Kerala Veterinary and Animal Sciences University, Pookode, Wayanad, Kerala

1. M.V.Sc Scholar and ${ }^{* *}$ corresponding author email: rashiumesh18@gmail.com, ph. 8904795793

2. Professor and Head

3. Associate Professor

4. Assistant Professor

5. Professor and Head, Department of Veterinary Epidemiology and Preventive Medicine

Copyright: () 2021 Rashi et al. This is an open access article distributed under the terms of the Creative Commons Attribution 4.0 International License (http://creativecommons.org/licenses/by/4.0/), which permits unrestricted use, distribution, and reproduction in any medium, provided the original author and source are credited. 
virus and the host affected. Even low virulence strains of the virus may produce severe disease when co-infected with other organisms or due to adverse environmental conditions (OIE, 2018).

The infection can occur by inhalation, ingestion of contaminated material and by direct contact. The isolates show variation in their pathogenicity and as well as in the organs they affect and have considerable influence on mode of spread of infection between the birds (Alexander, 1988). Based on the pathogenicity, the virus is classified into five pathotypes viz., viscerotropic velogenic, neurotropic velogenic, mesogenic, lentogenic and asymptomatic enteric NDV (Beard and Hanson, 1984). The severity of disease varies from mild local infection to lethal systemic infection. The clinical signs of the disease depend on the virulence of the infecting virus, immune status of the host, age of the host, the species of bird and environmental conditions (Seal et al., 2000).

Proper diagnosis is essential for controlling the disease. Even though virus isolation is the gold standard test for diagnosis of ND, due to the wide use of live vaccine and its interference during the isolation, pathogenicity tests or nucleotide sequencing is required for viral characterisation. In vivo pathogenicity tests like mean death time (MDT) in embryonated chicken eggs (ECE), intracerebral pathogenicity index (ICPI) and intravenous pathogenicity index (IVPI) are commonly employed for identification of pathotypes of the virus (Alexander, 2000).

Several outbreaks of ND were reported in Kerala for the past several years even in vaccinated flocks. Hence, this study was conducted to isolate the NDV prevalent in Kerala and subsequently, pathotype them by ICPI and MDT tests.

\section{Materials and methods}

\section{Sample collection and processing}

Tissue samples (lungs, liver, spleen, kidney, brain, heart and intestine) from the dead andailingbirdsshowinglesions/signssuggestive of ND presented to Departments of Veterinary Pathology and Veterinary Microbiology, College of Veterinary and Animal Sciences, Mannuthy were collected in phosphate buffer saline (PBS).
Brain and intestine were collected separately and all other organs from a single bird were pooled. The tissue samples were homogenised and the 20 per cent (w/v) suspension was subjected to centrifugation at $3000 \mathrm{rpm}$ for 10$15 \mathrm{~min}$. The supernatant obtained was filtered through membrane syringe filter $(0.22 \mu \mathrm{m})$ and antibiotic-antimycotic solution containing penicillin $(1,00,000$ Units/ $\mu \mathrm{L})$, streptomycin (100 mg/ $\mu \mathrm{L})$ and amphotericin B $(200 \mu \mathrm{g} / \mu \mathrm{L})$ was added, incubated at $37^{\circ} \mathrm{C}$ for $30 \mathrm{~min}$. and was used as inoculum for virus isolation.

\section{Isolation of virus using embryonated chicken eggs}

It was performed according to OIE (2018). Tissue suspension treated with antibiotic-antimycotic solution $(0.1 \mathrm{~mL})$ was inoculated into nine to eleven day-old ECE intra-allantoically. Three eggs were inoculated per sample and one control egg was inoculated with $0.1 \mathrm{~mL}$ of PBS. They were incubated at $37^{\circ} \mathrm{C}$ for five days and candled twice daily. The death of the embryo within $24 \mathrm{~h}$ post inoculation (PI) was considered as non-specific and discarded, while embryos died after $24 \mathrm{~h} \mathrm{PI}$ were chilled at $4^{\circ} \mathrm{C}$ overnight and viable embryos after five days PI were terminated by chilling at $4^{\circ} \mathrm{C}$ overnight. Next day, the amnio-allantoic fluid (AAF) was harvested and spot haemagglutination (HA) test was conducted with 10 per cent chicken erythrocytes. The embryos were observed for lesions. The samples were considered as negative only after three blind passages.

\section{Confirmation of the virus isolates by haemagglutination inhibition $(\mathrm{HI})$ test}

The spot HA positive AAF samples were subjected for plate HA test using one per cent chicken RBC. They were confirmed by $\mathrm{HI}$ test using NDV specific antiserum maintained in the department. Four HA units were calculated and AAFs were diluted accordingly and used for $\mathrm{HI}$ test. The $\mathrm{HA}$ and $\mathrm{HI}$ tests ( $\beta$-method) were done as per FAO (2002).

\section{Pathotyping of NDV isolates}

In vivo tests namely ICPI and MDT were performed for biological characterisation of the confirmed isolates. The experimental work on animals were carried out after obtaining approval from Institutional Animal Ethics 
Committee (IAEC).

\section{ICPI test}

Day-old chicks were used for the test according to OIE (2018). The AAF was diluted (1:10) in normal saline (NS) and $0.05 \mathrm{~mL}$ was inoculated intracranially into chicks. Ten birds were inoculated per isolate and control birds $(\mathrm{N}=10)$ were inoculated with $0.05 \mathrm{~mL}$ of NS. These birds were examined every $24 \mathrm{~h}$. for eight days and scored accordingly. The score 0 was given to normal birds, 1 to sick birds and 2 to dead birds. Birds with paralysis and unable to drink and feed were killed humanely and taken dead for next observations. Mean score per bird per observation was made over a period of eight days is the ICPI value.

\section{MDT test}

The test was performed in nine to eleven dayold ECE. Ten-fold dilution of AAF was made from $10^{-1}$ to $10^{-9}$ in NS. Dilutions from $10^{-6}$ to $10^{-9}$ at the rate of $0.1 \mathrm{~mL}$ was inoculated into ECE intra-allantoically as per the protocol of FAO (2002). Five eggs were inoculated per dilution. The remaining part of the dilutions $\left(10^{-6}\right.$ to $\left.10^{-9}\right)$ made were retained at $4^{\circ} \mathrm{C}$ and inoculated into five eggs per dilution after $8 \mathrm{~h}$. All the eggs were incubated at $37^{\circ} \mathrm{C}$ for seven days. The embryos were observed for death twice daily. After seven days, the highest dilution of the virus which kills all the inoculated embryo was taken as minimum lethal dose (MLD). The mean time in hours, taken for MLD to kill all the embryos was taken as MDT.

\section{Results and discussion}

The samples were collected from a total of 55 birds (Table 1). Out of which, 45 tissue samples were collected from ailing birds. These birds showed clinical signs like diarrhoea, oedema of head and respiratory distress. Torticollis and paralysis were noticed in some of the birds. Similar observations were made by Chowdhary et al. (2020) in the birds from which NDV was isolated. Tissue samples were collected from ten recently dead birds. Pinpoint haemorrhages in the proventriculus, caecal tonsils, congestion of the lung and liver were the predominantly observed postmortem lesions (Fig. 1). Even though the clinical symptoms and post-mortem lesions aids in diagnosis of ND in field conditions, the definitive diagnosis could not be arrived solely on these findings. Hence, virus isolation and characterisation is necessary (Hines and Miller, 2012).

On virus isolation, AAF of eight samples revealed HA on spot test (Fig. 2) and produced lesions in embryo. All the eight samples were from chicken. Among the eight samples, five were from tissue samples collected from ailing birds and three were from dead birds. The embryos inoculated with these samples died within three to five days $\mathrm{PI}$. and lesions like generalised congestion, pinpoint haemorrhages in occipital region and congestion of chorio-allantoic membrane were observed in first passage and these lesions were prominent in third passage (Fig. 3). These results are in agreement with the findings of Balachandran et al. (2014) and Qosimah et al. (2018).

Plate HA test for the AAF which gave positive spot HA was carried out. The HA titre of the eight samples varied from 4 to $10 \log _{2}$ (Table 2). All these samples were confirmed as NDV by $\mathrm{HI}$ test and the $\mathrm{HI}$ titres were found to be $4 \log _{2}$. The HA might also be due to other

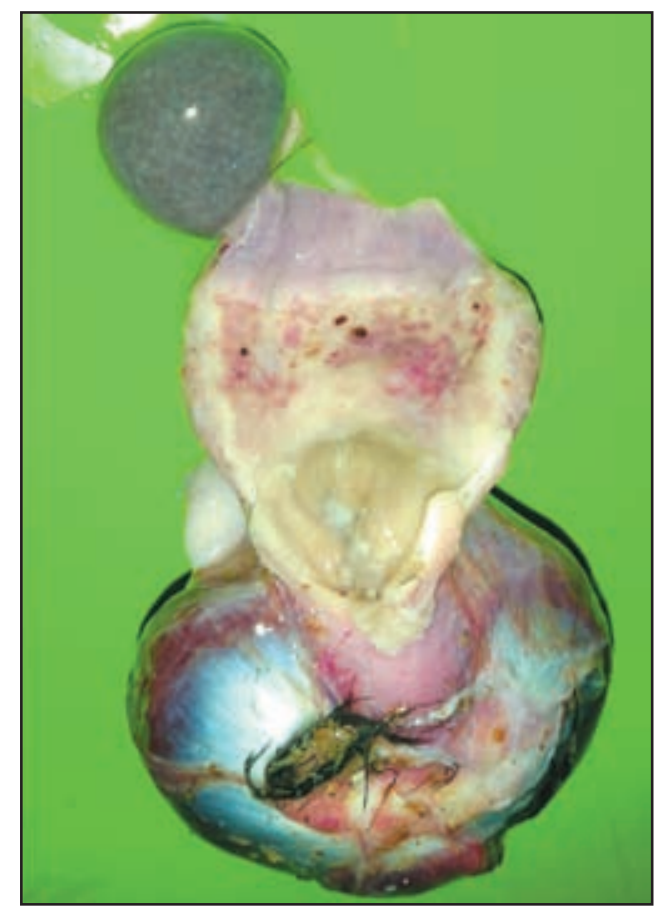

Fig. 1. Pinpoint haemorrhages in the summit of papillae of proventriculus 


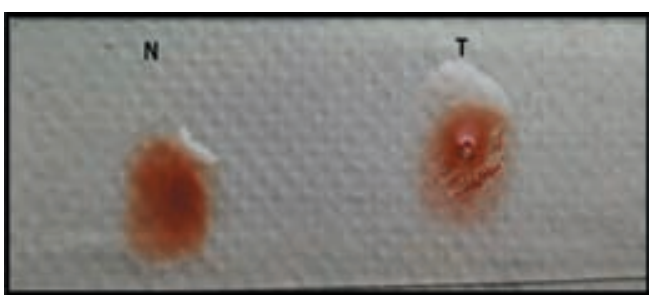

Fig. 2. Spot haemagglutination test

$\mathrm{N}$ : Negative control

T: Harvested AAF - Positive

serotypes of NDV or due to Influenza A viruses, hence $\mathrm{HI}$ tests has to be carried out using NDV specific antiserum. Inhibition of HA property of the viruses in $\mathrm{HI}$ test confirms the presence of NDV (Alexander, 2000).

The pathogenicity of the virus is mainly due to fusion ( $F$ ) protein hence, along with virus isolation the evaluation of virulence of the viral isolates by ICPI test or amino acid sequencing at fusion protein cleavage site (FPCS) of $F$ protein is necessary (OIE, 2018). The ICPI and MDT tests were conducted for the NDV viral isolates obtained in this study for the assessment of virulence. The ICPI values for eight isolates varied from 0.75 to 1.53 . During the ICPI test, birds showed clinical signs like torticollis, paralysis, depression and huddling behaviour. The MDT was found to be between 54 h. to 79.2 h.

Table 1. Details of the samples collected

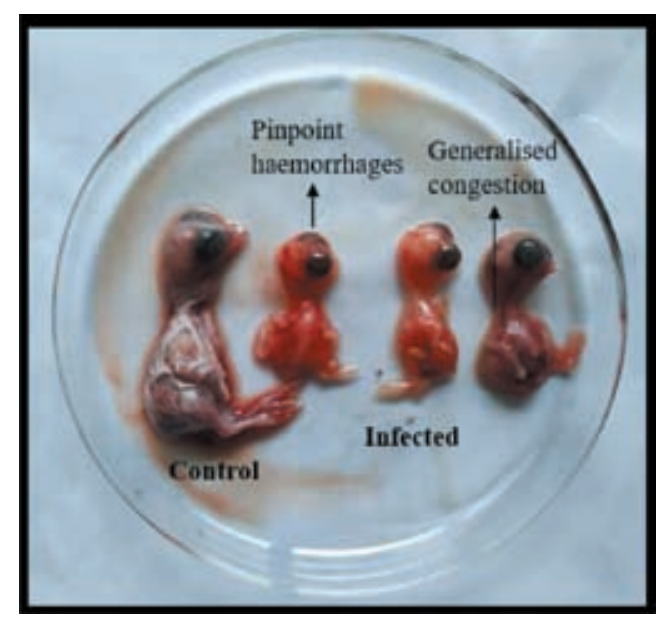

Fig. 3. Characteristic post-inoculation changes of the embryo (9-11 day-old)

Alexander (1998) reported that velogenic and mesogenic NDV showed ICPI values of 0.7 to 1.5 and $>1.5$, respectively. Hanson and Brandly (1955) classified NDV based on MDT. The viruses with MDT 60 h., 60 to $90 \mathrm{~h}$. and $>90 \mathrm{~h}$. were grouped as velogenic, mesogenic and lentogenic viruses. In the present study, three of the eight isolates were grouped under velogenic and the remaining five belonged to mesogenic group (Table 2). Velogenic and mesogenic group of viruses show similar amino acid sequence at FPCS region i.e., polybasic amino acid sequence. Based on molecular characterisation of $F$ gene

\begin{tabular}{|c|c|c|c|c|c|c|}
\hline \multirow{2}{*}{$\begin{array}{l}\text { SI. } \\
\text { No. }\end{array}$} & \multirow{2}{*}{ Condition of bird } & \multicolumn{5}{|c|}{ Species } \\
\hline & & Chicken & Quail & Duck & African love bird & Total \\
\hline 1 & Dead birds & 10 & - & - & - & 10 \\
\hline 2 & Ailing birds & 33 & 8 & 3 & 1 & 45 \\
\hline & Total & 43 & 8 & 3 & 1 & 55 \\
\hline
\end{tabular}

Table 2. HA, HI titre and pathogenicity indicies of NDV isolates

\begin{tabular}{|c|c|c|c|c|c|c|c|}
\hline $\begin{array}{c}\text { SI. } \\
\text { No. }\end{array}$ & Isolates & $\begin{array}{c}\text { HA titre } \\
\left(\mathbf{L o g}_{\mathbf{2}}\right)\end{array}$ & $\begin{array}{c}\text { HI titre } \\
\left(\mathbf{L o g}_{\mathbf{2}}\right)\end{array}$ & ICPI & MDT (h.) & Pathotype & Species \\
\hline 1 & NDV-S5 & 9 & 4 & 1.5 & 60 & Velogenic & Chicken \\
\hline 2 & NDV-S6 & 10 & 4 & 0.98 & 62.4 & Mesogenic & Chicken \\
\hline 3 & NDV-P2 & 8 & 4 & 0.75 & 75.6 & Mesogenic & Chicken \\
\hline 4 & NDV-S9 & 6 & 4 & 1.35 & 62.4 & Mesogenic & Chicken \\
\hline 5 & NDV-P4 & 5 & 4 & 0.9 & 73.2 & Mesogenic & Chicken \\
\hline 6 & NDV-S17 & 4 & 4 & 1.51 & 58.8 & Velogenic & Chicken \\
\hline 7 & NDV-S18 & 4 & 4 & 1.53 & 54 & Velogenic & Chicken \\
\hline 8 & NDV-P6 & 4 & 4 & 1.03 & 79.2 & Mesogenic & Chicken \\
\hline
\end{tabular}


the virulent viruses cannot be distinguished into velogenic and mesogenic pathotypes hence, biological characterisation of the virus by pathogenicity tests like MDT, ICPI and IVPI tests is required (Balachandran et al., 2014).

\section{Coclusion}

In the present study, it was found that virulent type of NDV (both mesogenic and velogenic) is prevalent in Kerala. The pathotype of the virus could be identified in in vivo pathogenicity tests and is useful during the surveillance of the disease. Strict biosecurity measures and vaccination regimen are to be followed for prevention and control of ND. For the success of vaccination programme, characterisation of the virus is necessary for the selection of a proper vaccine candidate.

\section{Acknowledgement}

The authors are thankful to Kerala Veterinary and Animal Sciences University for providing all facilities for the completion of this work.

\section{Conflict of interest}

The authors declare that they have no conflict of interest.

\section{References}

Alexander, D. J. 1988. Newcastle disease diagnosis. In: Newcastle Disease. $\left(1^{\text {st }}\right.$ Ed.). Kluwer Academic Publishers. Norwell, Massachusetts, pp. 147- 161.

Alexander, D. J. 1997. Newcastle disease and other Paramyxoviridae infections, In: Calnek, B. W., Barnes, H. J., Beard, C. W., McDougald, L. and Saif J. Y. M. (eds.), Diseases of Poultry. (10 th Ed.). lowa State University, Ames, lowa, pp. 541- 569.

Alexander D. J. 1998. Newcastle disease virus and other avian paramyxoviruses. In: Swayne, D. E., Glisson, J. R., Jackwood, M. J., Pearson, J. E. and W. M. Reed. (eds.), A Laboratory Manual for the Isolation and Identification of Avian Pathogens. (4 $4^{\text {th }}$ Ed.). The American Association of Avian Pathologists, Kennett Square, Pennsylvania, pp. 156163.
Alexander, D. J. 2000. Newcastle disease and other avian paramyxoviruses. Rev. Sci. Tech. 19: 443-462.

Balachandran, P., Srinivasan, P., Sivaseelan, S., Balasubramaniam, G. A. and Murthy, T. G. K. 2014. Isolation and characterization of Newcastle disease virus from vaccinated commercial layer chicken. Vet. World. 7: 457-462.

Beard, C.W. and Hanson, R. P. 1984. In: Hofstad, M. S. (ed.), Diseases of Poultry. (8 ${ }^{\text {th }}$ Ed.). lowa State University Press, Ames, pp. 452-470.

Chowdhary, M., Nashiruddullah, N., Roychoudhury, P., Bhat, A., Ahmed, J. A., Kour, K. and Sood, S. 2020. Molecular and virulence characterization of Newcastle disease virus in fowls and pigeons from Jammu, India. Indian J. Anim. Res. 54: 1279-1284.

FAO [Food and Agricultural Organisation]. 2002. A Basic Laboratory Manual for the Small-Scale Production and Testing of I-2 Newcastle Disease Vaccine. Food and Agricultural Organisation, Italy, 130p.

Hanson, R. P. and Brandly, C. A. 1955. Identification of vaccine strains of Newcastle disease virus. Science. 122: 156-157.

Hines, N. L. and Miller, C. L. 2012. Avian paramyxovirus serotype-1: A review of disease distribution, clinical symptoms, and laboratory diagnostics. Vet. Med. Int. 2012: 1-17.

OIE [Office International des Epizooties]. 2018. Manual of Diagnostic Tests and Vaccines for Terrestrial Animals (Mammals, Birds and Bees). World Organization for Animal Health, Paris, 573p.

Qosimah, D., Murwani, S., Sudjarwo, E. and Lesmana, M. A. 2018. Effect of Newcastle disease virus level of infection on embryonic length, embryonic death, and protein profile changes. Vet. World. 11: 1316.

Seal, B. S., King, D. J. and Meinersmann, R. J. 2000. Molecular evolution of the Newcastle disease virus matrix protein gene and phylogenetic relationships among the paramyxoviridae. Virus Res. 66: 1-11. 